\title{
TRANSURETHRAL BLADDER BIOPSY AFTER POST INTRAVESICAL BCG THERAPY FOR SUPERFICIAL BLADDER CANCER PATIENTS
}

\author{
By \\ WAEL MORSY A. EL-SAYED ${ }^{1 *}$, TAREK ABDEL KADER SALLAM ${ }^{1}$ and \\ AYMAN T. A. MORSY ${ }^{2^{* \star}}$ \\ Military Medical Academy, Cairo, $11291^{1}$ and Consultant Tropical \\ Medicine and Fever ${ }^{2}$,Egypt ( ${ }^{*}$ Correspondence: w_el_sayed@hotmail.com, \\ ayman.tosson@med.asu.edu.eg)
}

\section{Abstract}

This study evaluated the role of routine biopsy from the site of previously resected superficial bladder tumor three months following resection and intravesical BCG therapy in the presence of negative urine cytology and cystoscopy. Thirty-two patients (21males and 11 females) with high-risk superficial transitional cell carcinoma (TCC) of the bladder were followed prospectively. All patients received a single six weeks course of intravesical Bacillus ChalmetteGuerin (BCG). Three months following resection, urine cytology was done. Cystoscopy was then performed and a routine biopsy from the previous resection site was taken. All patients included in the study had negative urine cytology and cystoscopy at the time of biopsy. Four $(12.5 \%)$ patients were having TCC although they had negative urine cytology and cystoscopy at the time of biopsy. The histological recurrence was corresponded to T1G1 in two patients and T1G2 in the other two patients and the pathology after BCG treatment for the four patients was the same as before instillation. There were no statistically significant differences between patients with positive and negative biopsies with regard to the stage and grade of the tumor before resection, or the number of resected lesions.

Keywords: Egypt, Patients, BCG, Tumor bladder, Superficial.

\section{Introduction}

Generally, the stage $\mathrm{T} 1$ bladder cancers invade the lamina propria of the bladder and, despite sharing many of genetic features of muscle-invasive bladder cancers, were classified as non-muscle-invasive or superficial tumors (Jordan and Meeks, 2019). The initial treatment is transurethral resection with the attempt to remove all tumors. This must provide an accurate histological grade and stage, and from this information a prognosis can be determined (Herr, 1997). The important predictive factors that correlated with a new occurrence or true recurrence and development of a subsequent tumor with muscle invasion (high risk group) are a high tumor grade, lamina propria invasion $\mathrm{T} 1$, a positive cytology following resection, multifocal tumors, dysplasia, or carcinoma in situ (CIS) from mucosal biopsies of normal appearing urothelium, and a prior history of bladder cancer (Amling, 2001. The recurrence rate varied from 30 to $80 \%$ and progression with the muscle invasive tumor up to $30 \%$ (Stapp et al, 2000).
The intravesical Bacillus Chalmette-Guerin (BCG) instillation is recommended as the first choice to treat high-risk group patients (Van Der Meijden et al, 2003). After BCG treatment, high-grade carcinomas are cured in long term in one third of the cases, with recurrence in the same form in one third of the cases, and in second one third, evolved into an infiltrating form (Lebert, 1998). An accurate diagnosis of recurrence of the highgrade tumor was of the utmost importance, since it implied the major worsening of prognosis and led to the decision to perform cystectomy (Herr, 1992).

To assess response of intravesical BCG, urologists evaluated patients after intravesical therapy with transurethral bladder biopsies at time of 3-month cystoscopy (Skemp and Fernandes, 2002). This practice of routine bladder biopsy at 3-6 months; but many authors suggested instead that biopsies only to be carried out in selected patients based on initial pathology or 3-month cystoscopy and cytology (Highshaw et al, 2003; Murakami, 2007; Chen et al, 2018). 
The study aimed to evaluate routine biopsy role from the site of resected superficial bladder tumor 3 months after resection and intravesical BCG therapy in patients with negative urine cytology and cystoscopy.

\section{Subjects and Methods}

Thirty-two patients with high-risk bladder superficial transitional cell carcinoma were prospectively studied over the year 2018 .

The patients were examined by urine analysis, serum creatinine (Callens and Bartges, 2015), abdominal and pelvic US (Babjuk et $a l, 2017)$ and intravenous urography (IVU). Diagnosis was done by cystoscopy \& complete lesion transurethral resection. All received a course of 6-weeks BCG. Dose was
$(90 \mathrm{mg})$ diluted in $(50 \mathrm{ml})$ normal saline solution instilled by a urinary catheter, 2 weeks elapsed after the TURT before BCG treatment (Lamm et al, 2000). Post-BCG instillation, patients were asked to hold the fluid in their bladders for about $2 \mathrm{hrs}, \&$ frequently change their positions to distribute treatment throughout urinary bladder. Follow up was done 3 months after lesion trans-urethral resection by urine cytology and scheduled for check cystoscopy where a routine biopsy was taken from resected tumor site. All patients showed negative urine cytology and cystoscopy at biopsy time.

\section{Results}

Details were given in tables (1, $2 \& 3)$.

\begin{tabular}{|c|c|}
\hline Pathology & Number $(\%)$ \\
\hline Tis (CIS) & $2(6.3)$ \\
\hline Ta G2 & $6(18.8)$ \\
\hline Ta G3 & $2(6.3)$ \\
\hline T1G1 & $11(34.4)$ \\
\hline T1G2 & $9(28.1)$ \\
\hline T1G3 & $2(6.3)$ \\
\hline Lesion number $=1$ & $25(78.1)$ \\
\hline Lesion number $=2$ & $5(15.6)$ \\
\hline Lesion number $=3$ & $2(6.3)$ \\
\hline
\end{tabular}

Thirty-two patients ( 21 males \& 11 femaltillation showed Tis (CIS) in $2(6.3 \%)$ paes) with ages 32-75 years (mean 55.6) were tients, Ta in $8(25 \%)$, and T1 in $22(68.7 \%)$, enrolled. Lesions pathology before BCG ins- with majority of single lesion in $78.1 \%$.

Table 2.Biopsy results after BCG course

\begin{tabular}{|l|c|}
\hline Pathology & Number (\%) \\
\hline Cystitis & $14(43.8 \%)$ \\
\hline Cystitis with dysplasia & $7(21.9 \%)$ \\
\hline Cystitis cystica \& cystitis glandular & $3(9.4 \%)$ \\
\hline Polyposis cystitis & $4(12.5 \%)$ \\
\hline TCC & $4(12.5 \%)$ \\
\hline
\end{tabular}

Biopsy was done after six weeks of BCG course, four patients showed TCC, although at the biopsy time.

Table 3: Comparison between patients with negative or positive biopsies

\begin{tabular}{|c|c|c|}
\hline Pathology & Negative biopsy No. (\%) & Positive biopsy No. (\%) \\
\hline T stage : Tis & $2(7.1 \%)$ & 00 \\
\hline$: \mathrm{Ta}$ & $8(28.6 \%)$ & 00 \\
\hline :T1 & $18(64.3 \%)$ & $4(100 \%)$ \\
\hline Total & 28 & 4 \\
\hline Grading: G1 & $9(34.6 \%)$ & $2(50 \%)$ \\
\hline : G2 & $13(50 \%)$ & $2(50 \%)$ \\
\hline : G3 & $4(15.4 \%)$ & 00 \\
\hline Total & 26 & 4 \\
\hline Lesions: 1 & $21(75 \%)$ & $4(100 \%)$ \\
\hline$: 2$ & $5(17.8 \%)$ & 00 \\
\hline$: 3$ & $2(71.4 \%)$ & 00 \\
\hline Total & $28(87.5 \%)$ & $4(12.5 \%)$ \\
\hline
\end{tabular}

In four positive biopsied patients, histological recurrence compared to T1G1 in two patients \& T1G2 in another two patients. Pathology did not change as before instillation, without significant differences between patients with positive or negative biopsies, as to tumor stage and grade before resection, or resected lesions number. 


\section{Discussion}

Bladder cancer is among the top ten most common cancer types in the world, with approximately 550,000 annual new cases (Richters et al, 2020). Bladder cancer is the commonest urogenital malignancy, after prostate cancer (Bray et al, 2018). It is the commonest genitourinary cancer in USA with symptoms mimics those of a urinary tract infection that time delayed diagnosis (Farling, 2017). The major risk factors for bladder cancer are environmental and occupational factors (Kiiluk et al, 2012), tobacco smoking besides, from lung cancer (Sasco et al, 2004), exposure to toxic industrial chemicals and gases, bladder inflammation due to microbes, parasites, and some medications side-effects as well as some adverse side-effects of medications (Zhang and Zhang, 2015). Among the parasites encountered in Egypt and cause the bladder cancer are Schistosoma haematobium (Gaber et al, 2020), and chronic Trichomonas vaginalis was associated with prostate cancer (Saleh et al, 2021). Othman and Soliman (2015) considered that schistosomiasis was plagued the Egyptians since the ancient time.

Boyd (2003) in USA reported that bladder cancer still the leading risk of malignant neoplasm in men. The Bacillus Calmette-Guerin (BCG) was a accepted treatment for superficial bladder malignancy. Khaled (2005) in Egypt found that bladder cancer was the commonest malignancy among the Egyptian males $(16 \%)$, with $>7900$ annual deaths, strikingly higher than many countries worldwide. Fedewa et al. (2009) in Egypt added that the bladder cancer was the commonest malignancy among Egyptian males due to $S$. haematobium, a major risk factor for squamous cell carcinoma (SCC), but, transitional cell carcinoma (TCC) incidence increased, while SCC declined. Salem and Mahfouz (2012) in Egypt reported that the incidence pattern of various histologic types of bladder cancer were changed, with most cases now transitional cell carcinoma, in contrast to the findings in the earlier Egyptian series. Antoni et al. (2017) in France found that the recorded patterns and bladder cancer incidence worldwide reflected the prevalence of tobacco smoking, but infection with $S$. haematobium and other risk factors were major cause nearly among all Arabian populations. Amin et al. (2019) in Egypt reported that the old concept that schistosomiasis associated with SCC must be re-evaluated as many cases were associated with TCC. They added that based on histopathological proved schistosomiasis was not accurate and led to irrelevant data. Hatta et al. (2021) in Malaysia correlated between $S$. haematobium and bladder cancer.

Moreover, BCG instillation treatment reduced the risk of progression of high-grade bladder cancer and carcinoma in situ (Van Der Meijden et al, 2005). However, as about $50 \%$ of complete responders may eventually experience recurrences with a risk of invasion and/or extravesical recurrence, early and precise detection of cases resistant to BCG instillation is necessary (Jakse et al, 2001). Lenis et al. (2020) in USA reported that the bladder cancer being a common malignancy in women and the $4^{\text {th }}$ most common malignancy in men. They added that while intravesical BCG remained the mainstay of therapy for intermediate $\&$ high-risk nonmuscle-invasive bladder cancer, therapeutic options for muscle-invasive and advanced disease included immunotherapy with checkpoint inhibition, targeted therapies, \& antibody-drug conjugates.

In the present study, no cystoscopy biopsies were positive in patients with mucosal erythema and negative cytology. Dalbagni et al. (1999) in USA reported that bladder biopsy is not necessary in patients 3 months after receiving BCG who have a normal office cystoscopy or an erythematous bladder and normal urine cytology. Skemp and Fernandes (2002) in USA also found that patients with papillary TCCB with negative cystoscopic and negative urine cytologic results 
were safely be spared routine transurethral bladder biopsy with its associated cost and morbidity. But, patients with carcinoma in situ were very likely to have persistent abnormal cytologic or abnormal cystoscopic results warranting investigation with biopsy and benefited from routine scheduled biopsy. Highshaw et al. (2003) didn't do cytology examinations, but recommended limiting biopsies to patients with suspicious cystoscopy findings. Guy et al. (2006) in France found that this tactic resulted in four false negatives out of 84 patients with a negative cystoscopy, and the four false-negative patients presented high-grade tumors on histology. Murakami et al. (2007) in Japan did not recommend the routine bladder biopsy in patients with negative cystoscopy and negative urine cytology. They found that of $1 / 48$ patients with negative cystoscopy and urine cytology had a positive bladder biopsy.

In the present study, only $4 / 32(12.5 \%)$ patients with negative urine cytology and cystoscopy showed positive bladder biopsies with high-risk superficial urothelial tumor. Hara et al. (2009) reported that false-negative cytology was attributed to the intravesical BCG therapy effect, which decreased urine cytology sensitivity.

The sensitivity of urine cytology for recurrence of high-risk tumors was a parameter varied from $44 \%$ up-to $97 \%$ (Bastacky et al, 1999). The sensitivity was reduced by its inability to detect low-grade tumors whose risk of progression was very low, and therefore do not require early diagnosis. Otherwise, interpretation of urine cytology findings after BCG treatment was difficult without an expert pathologist (Molinie et al, 2003). Guy et al. (2006) found that the sensitivity of cytology was $56 \%$, and its specificity was $92 \%$ and cystoscopy and urine cytology combined had a sensitivity of $100 \%$ for the detection of bladder recurrence after BCG treatment. They concluded that the negativity of these two examinations therefore makes it possible to avoid systematic biopsies and, consequently the useful- ness of cystoscopy as an additional procedure. But, Lightfoot et al. (2012) reported that the previous studies that did not recommend biopsy with a negative cystoscopy and cytology had limitations. A variable number of biopsies (3-7) and location sites limited study (Skemp and Fernandes (2002).

Nevertheless, Guy et al. (2006) carried out thorough and systematic biopsies; and did not carry out biopsies on all patients undergoing treatment with a history of CIS or Ta disease, thereby limited their results. Murakami et al. (2007) in Japan found that routine transurethral biopsy of bladder for evaluating the response to BCG intravesical therapy was not indicated in patients who have no visible tumor on cystoscopy and negative urinary cytology. Lightfoot et al. (2012) concluded that patients with thorough and consistent biopsies of the bladder and prostate are more likely to have bladder cancer recognized, even in the negative cystoscopy and negative cytology.

Hara et al. (2009) in Japan reported that performing routine bladder biopsy and urine cytology helped in the early detection of the BCG-resistant cancer in 10/63 (16\%) patients with a normal appearing bladder mucosa on cystoscopy and negative cytology. May et al. (2003) in Germany prospectively carried out six random bladder biopsies on normal appearing urothelium in 1033 patients with bladder cancer, and in 128 (12.4\%) cancer was in areas of normal appearing urothelium. Improved understanding of the molecular biology and genetics of bladder cancer has evolved the way localized and advanced disease is diagnosed and treated.

While the intravesical BCG has remained the mainstay of therapy for the intermediate and high-risk non-muscle-invasive bladder cancer, the therapeutic options for muscleinvasive and advanced disease has expanded to include immunotherapy with checkpoint inhibition, targeted therapies, and antibodydrug conjugates (Peyrottes et al, 2021). 


\section{Conclusion}

Generally, bladder cancer ranged from unaggressive and noninvasive tumors that recur and commit patients to long-term invasive surveillance, to aggressive and invasive tumors with high specific mortality.

The present data which did not recommend biopsy in a negative cystoscopy and cytology showed limitations. The presence of controversies regarding whether to perform a routine transurethral bladder biopsy at the time of the first follow up after BCG instillation, it is better to combine routine biopsy with cytology and cystoscopy to increase the sensitivity of early detection of BCG failures and tumor recurrences.

\section{References}

Amin, HAA, Kobaisi, MH, Samir, RM, 2019: Schistosomiasis and bladder cancer in Egypt: Truths and myths. Open Access Maced. J. Med. Sci. 7, 23:4023-9

Amling, CL, 2001: Diagnosis and management of superficial bladder cancer. Curr. Probl. Canc. 25, 4:219-78.

Antoni, S, Ferlay, J, Soerjomataram, I, Znaor, A, Jemal, A, et al, 2017: Bladder cancer incidence and mortality: A global overview and recent trends. Eur. Urol. 71, 1:96-108.

Babjuk, M, Böhle, A, Burger, M, Capoun, O, Cohen, D, et al, 2017: EAU guidelines on nonmuscle-invasive urothelial carcinoma of the bladder: Update 2016. Eur Urol. 71, 3:447-61

Bastacky, S, Ibrahim S, Wilczynski, SP, Murphy, WM, 1999: The accuracy of urinary cytology in daily practice. Cancer 87:118-28. Boyd, LA, 2003: Intravesical Bacillus CalmetteGuerin for treating bladder cancer. Urol. Nurs. 23, 3:189-91, 199; quiz 192.

Bray, F, Ferlay, J, Soerjomataram, I, Siegel, RL, Torre, LA, et al, 2018: GLOBOCAN estimates of incidence \& mortality worldwide for 36 cancers in 185 countries. CA Canc. J. Clin. 68: 394-424.

Callens, AJ, Bartges, JW, 2015: Urinalysis. Vet Clin North Am Small Anim Pract. 45, 4: 621-37.

Chen, J, Cheung, F, Shi, R, Zhou, H, Lu, W, et al, 2018: PBMC fixation and processing for chromium single-cell RNA sequencing. J. Trans. Med. 16, 1:198.doi:10.1186/s12967-018-1578-4
Dalbagni, G, Rechtschaffen, T, Herr, HW 1999: Is transurethral biopsy of the bladder necessary after 3 months to evaluate response to $\mathrm{Ba}$ cillus Chalmette-Guerin therapy? J. Urol. 162: 708-9.

Farling, KB, 2017: Bladder cancer: Risk factors, diagnosis, and management. Nurse Pract. 42, 3:26-33.

Fedewa, SA, Soliman, AS, Ismail, K, Hablas, A, Seifeldin, IA, et al, 2009: Incidence analyses of bladder cancer in the Nile delta region of Egypt. Canc. Epidemiol. 33, 3/4:176-81.

Guy, L, Savareux, L, Molinie, V, Botto, H, et al, 2006: Should bladder biopsies are performed routinely after Bacillus Chalmette-Guerin treatment for high-risk superficial transitional cell cancer of the bladder? Eur. Urol. 50:516-20.

Gaber, DA, Shehata, MH, Amin, HAA, 2020: Online team-based learning sessions as interactive methodologies during the pandemic. Med. Educ. 54, 7:666-7.

Hara, T, Takahashi, M, Gondo, T, Nagao, K, Ohmi, C, et al, 2009: Discrepancies between cytology, cystoscopy and biopsy in bladder cancer detection after Bacillus Chalmette-Guerin intravesical therapy: original article: clinical investigation. Inter. J. Urol. 16:192-5.

Hatta, MNA, Mohamad Hanif, EA, Chin, SF, Neoh, HM, 2021: Pathogens and carcinogenesis: A review. Biology (Basel) 10, 6:5339.

Herr, HW, 1997: Tumor progression and survival in patients with T1G3 bladder tumors: 15year outcome. Br. J. Urol. 80:762-5.

Herr, HW, Wartinger, DD, Fair, WR, Oettgen, HF, 1992: Bacillus Chalmette-Guerin therapy for superficial bladder cancer: a 10-year follows up. J. Urol. 147:1020-3.

Highshaw, RA, Tanaka, ST, Evans, CP, deVere White, RW, 2003: Is bladder biopsy necessary at three or six months post BCG therapy? Urol. Oncol. 21:207-9.

Jakse, G, Hall, R, Bono, A, Carpentier, P, Spaander, JP, et al, 2001: Intravesical BCG in patients with carcinoma in situ of urinary bladder: Long-term results of EORTC GU Group Phase II Protocol 30861. Eur. Urol. 40:144-50. Jordan, B, Meeks, JJ, 2019: T1 bladder cancer: current considerations for diagnosis and management. Nat. Rev. Urol. 16, 1:23-34.

Khaled, HM, 2005: Systemic management of bladder cancer in Egypt: revisited. J. Egypt. Natl. Canc. Inst. 17, 3:127-31. 
Kiriluk, KJ, Prasad, SM, Patel, AR, Steinberg, GD, Smith, ND, 2012: Bladder cancer risk from occupational and environmental exposures. Urol. Oncol. 30, 2:199-211

Lamm, DL, Blumenstein, BA, Crissman, JD, Montie, JE, Gottesman, J, et al, 2000: Maintenance bacillus Chalmette-Guerin immunotherapy for recurrent TA, T1 \& carcinoma in situ transitional cell carcinoma of the bladder: A randomized Southwest Oncology Group Study.

J. Urol. 163:1124-9.

Lebret, T, Bohin, D, Kassardjian, Z, Her-ve, JM, Molinie, V, et al, 2000: Recurrence, progression and success in stage Ta grade 3 bladder tumors treated with low dose bacillus Chalmette-Guerin instillations. J. Urol. 163:63-7.

Lebret, T, Gaudez, F, Herve', JM, Barre, P, Lugagne, PM, et al, 1998: Low-dose BCG instillations in the treatment of stage T1 grade 3 bladder tumors: recurrence, progression and success. Eur. Urol. 34:67-2.

Lightfoot, AJ, Rosevear, HM, Nepple, KG, O'Donnell, MA, 2012: Role of routine transurethral biopsy and isolated upper tract cytology after intravesical treatment of high-grade nonmuscle invasive bladder cancer. Int. J. Urol. 19: 988-93.

Lenis, AT, Lec, PM, Chamie, K, Mshs, MD, 2020: Bladder Cancer: A Review. JAMA 324 , 19:1980-91.

Markowski, MC, Boorjian, SA, Burton, JP, Hahn, NM, Ingersoll, MA, et al, 2019: The Microbiome and genitourinary cancer: A collaborative review. Eur. Urol. 75, 4:637-46.

May, F, Treiber, U, Hartung, R, et al, 2003: Significance of random bladder biopsies in superficial bladder cancer. Eur. Urol. 44:47-0.

Molinie, V, Longchampt, E, Ouazana, D, Lebret, T, 2003: Bladder tumors and molecular markers: Current status and perspectives. Ann. Pathol. 23:306-31.

Murakami, T, Ebara, S, Saika, T, Irie, S, Takeda, K, et al, 2007: Routine transurethral biopsy of the bladder is not necessary to evaluate the response to Bacillus Chalmette-Guerin therapy. Acta Med. Okayama 61:341-4.

Naeem, A, Naseem, N, Anwar, S, Butt, S, Nagi, AH, 2015: Clinico-pathological pattern, classification and staging of urinary bladder carcinomas, a five years' experience at a Tertiary Care Hospital in Central Punjab. J. Ayub Med. Coll. Abbottabad. 27, 1:131-4.
Othman, AA, Soliman, RH, 2015: Schistosomiasis in Egypt: A never-ending story? Acta Trop.148:179-90.

Peyrottes, A, Ouzaid, I, Califano, G, Hermieu, JF, Xylinas, E, 2021: Neoadjuvant Immunotherapy for Muscle-Invasive Bladder Cancer. Medicina (Kaunas). 57, 8:769. doi: 10.3390/ medicina57080769

Richters, A, Aben, KKH, Kiemeney, LALM, 2020: The global burden of urinary bladder cancer: An update. World J. Urol. 38, 8:1895-904

Saleh, NE, Alhusseiny, SM, El-Zayady, WM, Aboelnaga, EM, El-Beshbishi, WN, et al, 2021: Trichomonas vaginalis serostatus and prostate cancer risk in Egypt: A case-control study. Parasitol Res. 120, 4:1379-88.

Salem, HK, Mahfouz, S, 2012: Changing patterns (age, incidence, and pathologic types) of Schistosoma-associated bladder cancer in Egypt in the past decade. Urology 79, 2:379-83.

Sasco, AJ, Secretan, MB, Straif, K, 2004: Tobacco smoking and cancer: A brief review of recent epidemiological evidence. Lung Canc. 45, 2:S3-9.

Skemp, NM, Fernandes, ET, 2002: Routine bladder biopsy after Bacillus Chalmette Guerin treatment: is it necessary? Urology 59:224-6.

Stapp, E, Deitch, AD, Ralpha, W, Devere, R W, 2000: Intravesical therapy and follow up of superficial transitional cell carcinoma of the bladder. Braz. J. Urol. 26:242-9.

Van Der Meijden, AP, Sylvester, RJ, Oosterlinck, W, Hoeltl, W, Bono, AV, 2003: Maintenance Bacillus Chalmette-Guerin for Ta T1 bladder tumors is not associated with increased toxicity: Results from a European Organization for Research \& Treatment of Cancer Genito-Urinary Group Phase III Trial. Eur. Urol. 44: 429-3.

Zhang, X, Zhang, Y, 2015: Bladder Cancer and Genetic Mutations. Cell. Biochem. Biophys. 73, 1:65-9.

Thanan, R, Murata, M, Ma, N, Hammam, O, Wishahi, M, El Leithy, et al, 2012: Nuclear localization of COX-2 in relation to the expression of stemness markers in urinary bladder cancer. Mediators Inflamm. 2012:165879. doi: 10.1155/ $2012 / 165879$. 